\title{
Misión y vocación
}

\section{universitária*}

Jesús González Lópes ${ }^{1}$

Estamos todos conscientes de la gran heterogeneidad y del distinto grado de desarrollo y maduración de cada una de las Universidades que conforman el sistema de Educación Superior en Latinoamérica, pero, no obstante ello, estimamos que existen también importantes elementos de convergencia y que la Universidad, en cuanto Universidad, cumple con el desarrollo socio-cultural de cada país idéntica misión, con fisonomías distintas, con postulados doctrinales distintos, con áreas disciplinares distintas y con grados y énfasis distintos de aportes en la docencia, en la investigación y en la extensión cultural.

No hay duda de que el lugar de encuentro es la identidad de la vocación universitaria y el común deseo de aportar lo mejor para bien de la comunidad nacional en que cada una se encuentra inserta.

Todas nuestras Universidades son instituciones de servicio, comprometidas con el cultivo y la difusión de saber y responsables de la formación integral de los profesionales de excelencia que el país necesita en las diversas actividades del quehacer nacional.

Mucho se habla hoy de educación; todos hablan de educación, existe en todos los pueblos una voluntad política de atención prioritaria a la educación. Pero nosotros hemos querido abordar el tema de la educación superior. ¿Por qué no hemos de hablar de Universidad los que en ella tenemos nuestra casa?

\footnotetext{
${ }^{*}$ Extracto y adaptación de la conferencia proferida durante la IV Asamblea del Consejo Pleno y Jornadas de Actualización de la Asociación de Universidad de América Latina y el Caribe para la Integración (AUALCPI)

${ }^{1}$ Rector de la Universidad Metropolitana de Ciencias de la Educación / Chile.
} 
Universidad, Auténtica Universidad por el riguroso cultivo del "universum" del saber: Ciencias, Humanidades, Artes y Tecnologías, en orden a la formación integral de profesionales idóneos.

Universidad en cuanto educación en y para lo superior. Educación practicada en un clima espiritual superior en la vivencia de los valores de verdad, de bien, de belleza y de integración. $Y$ una educación para lo superior, es decir, para hacer crecer en humanidad a las personas, a cada miembro de la comunidad académica: a estudiantes, a funcionarios y a profesores. Sólo así será capaz la Universidad de generar auténticos agentes humanizadores de cultura, o sea, comprometidos con la humanización del desarrollo tecnológico.

La Universidad debe propender, por vocación, a generar una comunidad científica cuya meta debe ser el riguroso cultivo del saber. Asimismo la Universidad debe generar una comunidad virtuosa en la práctica del bien. Sólo así estará contribuyendo eficazmente al rescate y a la promoción de valores humanos, los únicos capaces de constituirse en soportes y consistencia, vale decir, en fundamentos de todo el edificio de la racionalidad técnica a la que nos está riesgosamente empujando la modernidad.

La Universidad ha de constituirse siempre en cátedra del saber y en tribuna de la solidaridad, de la comunicación, de la tolerancia y del servicio a los demás, hasta llegar a estructurar en sus estudiantes actitudes existenciales de generosa autodonación.

Las preguntas que naturalmente surgen al intentar descubrir la identidad de este mundo Universidad, por el que transitamos todos los días, son siempre las mismas: ¿Qué es Universidad? ¿Cuál es su misión? ¿Cómo se juega nuestra vocación universitaria? ¿Cuáles son los requerimientos que la Universidad le impone al compromiso vocacional de cada uno?

La esencia de la Universidad, hoy y siempre, ha estado estrechamente referida a esa inquietud del hombre que indaga, busca, descubre y difunde aquello que ha llegado a apresar con su mente. De ahí que la Universidad es la fuente fundamental de la cultura.

Por definición y por vocación, la Universidad ha optado por el saber y por el progreso tecnológico, opción que le impone serias exigencias e inmensas responsabilidades. La Universidad debe constituirse en la comunidad humana e intelectual que se propone orientar el saber y la técnica hacia propósitos esencialmente humanos. Su interés es universal ya que sólo debe servir desinteresadamente a la verdad $y$ a su promoción entre los hombres. $Y$ al mismo tiempo y con idéntica intensidad, la Universidad debe representar un papel conductor en la instalación de los valores fundamentales del hombre.

Es misión fundamental de la Universidad el hacer crecer en humanidad al hombre a fin de que se constituya en un agente humanizador de la cultura, que es su creación esencial y su propiedad inalienable. 
La misión de la Universidad es generar pensamiento, generar ideas, generar saberes, en un clima de austeridad y hasta de soledad, en cuanto ésa es la forma propia de la génesis de toda idea, la que, nacida en el aislamiento de una conciencia individual, deberá vivir la esforzada aventura de abrirse paso hacia otros espíritus que esperan ansiosos la iluminación que todo pensamiento aporta al ser humano.

La producción austera y esforzada de los saberes en un ámbito de disciplina y de indagación empuja, necesariamente, a la transmisión de dichos saberes, ya organizados en estructuras curriculares, que se plasman en las tres funciones básicas del quehacer universitario: investigación, docencia y extensión.

Es en la Universidad donde el espíritu humano ha encontrado siempre el espacio propio para su natural expansión, vivificado por los objetos culturales.

Cito a este propósito al destacado profesor chileno Dn. Máximino Pacheco Gómez, quien en el discurso pronunciado en la Universidad de Chile con ocasión del otorgamiento de la Medalla "Rector Juvenal Hernández Jaque 1994” señalaba:

$$
\begin{aligned}
& \text { "El hombre tiene como misión esencial e ineludible, el vivir en el } \\
& \text { mundo de la cultura. El proceso de creación o transformación de objetos } \\
& \text { culturales es la actividad propia del hombre, es "su actividad"; y el } \\
& \text { conocer este mundo de objetos creados o transformados es un } \\
& \text { imperativo que pesa sobre su existencia. Ahora bien, dar a conocer al } \\
& \text { hombre este mundo de objetos culturales y despertar en él la pasión por } \\
& \text { la actividad creadora es la misión propia de la Universidad, su función } \\
& \text { primaria y central. La Universidad tiene como tarea fundamental la } \\
& \text { ilustración del hombre, la de mostrarle con claridad y precisión el } \\
& \text { gigantesco mundo de la Cultura". } \\
& \text { ("Discursos Académicos". Colección Testimonios Universitarios, Editorial } \\
& \text { Universitaria, Santiago, Chile, 1994, p.23). }
\end{aligned}
$$

Así, pues, la Universidad se identifica como la Institución al servicio de la creación cultural en beneficio de la sociedad y como el ámbito para la excelencia de la actividad de conquista y fruición de la verdad.

Pedro Laín Entralgo señalaba:

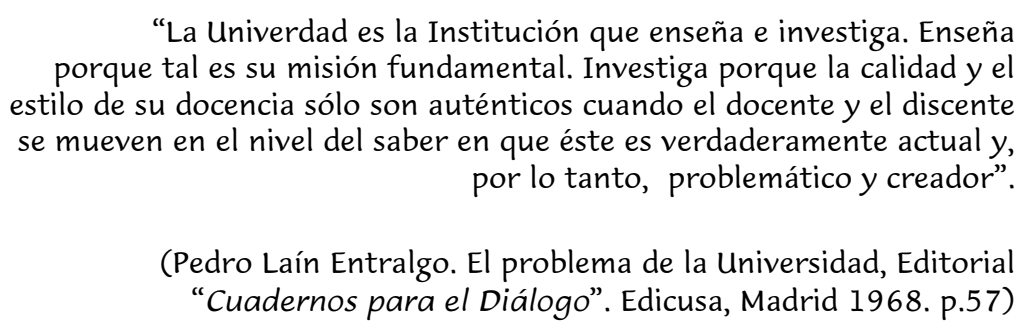

Sin lugar a dudas, las tres funciones básicas de la Universidad, docencia, investigación y extensión, están directamente ordenadas al desarrollo espiritual y material de la persona y de la sociedad. 
Existe una estrecha simbiosis entre cultura, innovación científica y tencológica y desarrollo social. La Universidad, con el fomento de las ciencias y tecnologías y con la formación de recursos humanos de excelencia contribuye, eficazmente, al desarrollo de la sociedad.

Un gran Rector de la Universidad de Chile, don Juvenal Hernández Jaque, en la Sesión del Consejo Universitario, el día 2 de octubre de 1933, al asumir en propiedad la Rectoría de la Universidad de Chile, emitía estos conceptos sobre la misión de la Universidad en la sociedad:

"Todo país que tiene el anhelo de perdurar y de salvar su historia, orienta las fuerzas vivas de que dispone hacia un fin determinado; $y$ no existe, de seguro, otra fuerza viva que supere a la "inteligencia" de un pueblo para mover sus proprios destinos. Por eso, la Universidad es la mejor aliada del progreso nacional y por eso, también, los países que tienen tradiciones espirituales de siglos, las cuidam como el fuego sagrado de la patria, otorgándole el fuero de la autonomía.

Las Instituciones Públicas pueden caer y transformarse sufriendo las contingencias del estado social y político del país; pero la Universidad, cuyo objetivo se pierde en el infinito, que sirve al interés supremo del grupo social, debe mantenerse siempre en funciones, haciendo la labor silenciosa de los que buscan el ideal frente a las zozobras de la realidad".

("Discursos Académicos. Colección Testimonios Universitarios, Editorial Universitaria, Santiago, Chile, 1994 p.20)

El quehacer universitario, en cuanto está ordenado hacia la formación integral de la persona, encierra la fuerza vivificante del auténtico humanismo; su objetivo fundamental es y será la persona, en un permanente cultivo de las actitudes, capacidades $y$ aspiraciones de sus profesores $y$ estudiantes, en un rico clima de confianza, de comunicación, de diálogo, de participación, de libertad, de criticidad $y$ de creatividad.

Estamos preocupados al constatar que hay en el ser humano un potencial interior espiritual que en el contexto cultural contemporáneo está apenas a medio explotar. Ahora bien, los educadores universitarios de hoy sólo podremos afianzar un mañana en armonía para la sociedad en la medida en que seamos capaces de producir el equilibrio entre las potencialidades de la racionalidad y los poderes de la conducta ética.

Debemos estar empeñados en convocar a todos los integrantes de nuestras comunidades universitarias a reinstalar en la vida académica los valores que nos consagrarán como verdaderos conductores frente a nuestros estudiantes, en una profunda vivencia de los valores de autenticidad, sencillez, probidad, veracidad, transparencia, solidaridad, equidad y justicia; $y$ todos ellos fundados en la plenitud del ser persona.

Nuestras Univerdidades deben estar atentas a todas las convocatorias del presente y disponibles para todos los desafíos del futuro. Nuestras Universidades deben estar decididas a asumir su misión 
de proyectarse significativamente en la sociedad y de contribuir eficazmente a su desarrollo, mediante la generación y transmisión del saber, la conservación e incremento del patrimonio artístico nacional, la formación de profesionales de excelencia en las diversas disciplinas y tecnologías que contribuyan a la generación de políticas y estrategias de desarrollo nacional, en la producción de medios de calidad, entre otras posibilidades de desarrollo. Y todo ello, cimentado en sólidos principios, dentro de un estilo de acción que ha de caracterizarse por una profunda convicción humanista, que resalte la dignidad de la persona y que promueva la vivencia de valores éticos; por una conciencia de su condición de comunidad abierta a su entorno, puesta al servicio del bien común; por una defensa permanente de la libertad y de la autonomía universitarias; por la expresión de un sano pluralismo, que invite a una efectiva integración de voluntades en el quehacer común, a través de un diálogo sostenido, enriquecido por el consenso y el respeto a las ideas de los demás; por la búsqueda laboriosa de la excelencia académica, entendida como un afán en el mejoramiento de la calidad personal, profesional e institucional; por la práctica de una sana participación democrática universitaria y por un profundo compromiso institucional de todos sus integrantes.

Debemos estar comprometidos en aportar nuestras propuestas institucionales en el contexto de este proceso modernizador.

La Universidad no podría eludir hoy su responsabilidad en la formación de sus estudiantes en los valores de justicia, de solidariedad, de servicio. Todos sus programas curriculares deben apuntar a una nutrida oferta de valores con miras a la dignificación del otro, a fomentar la vida en compañía, en contraposición a la cultura tecnificada que nos está arrojando a la frivolidad de la autosuficiencia individualista. 


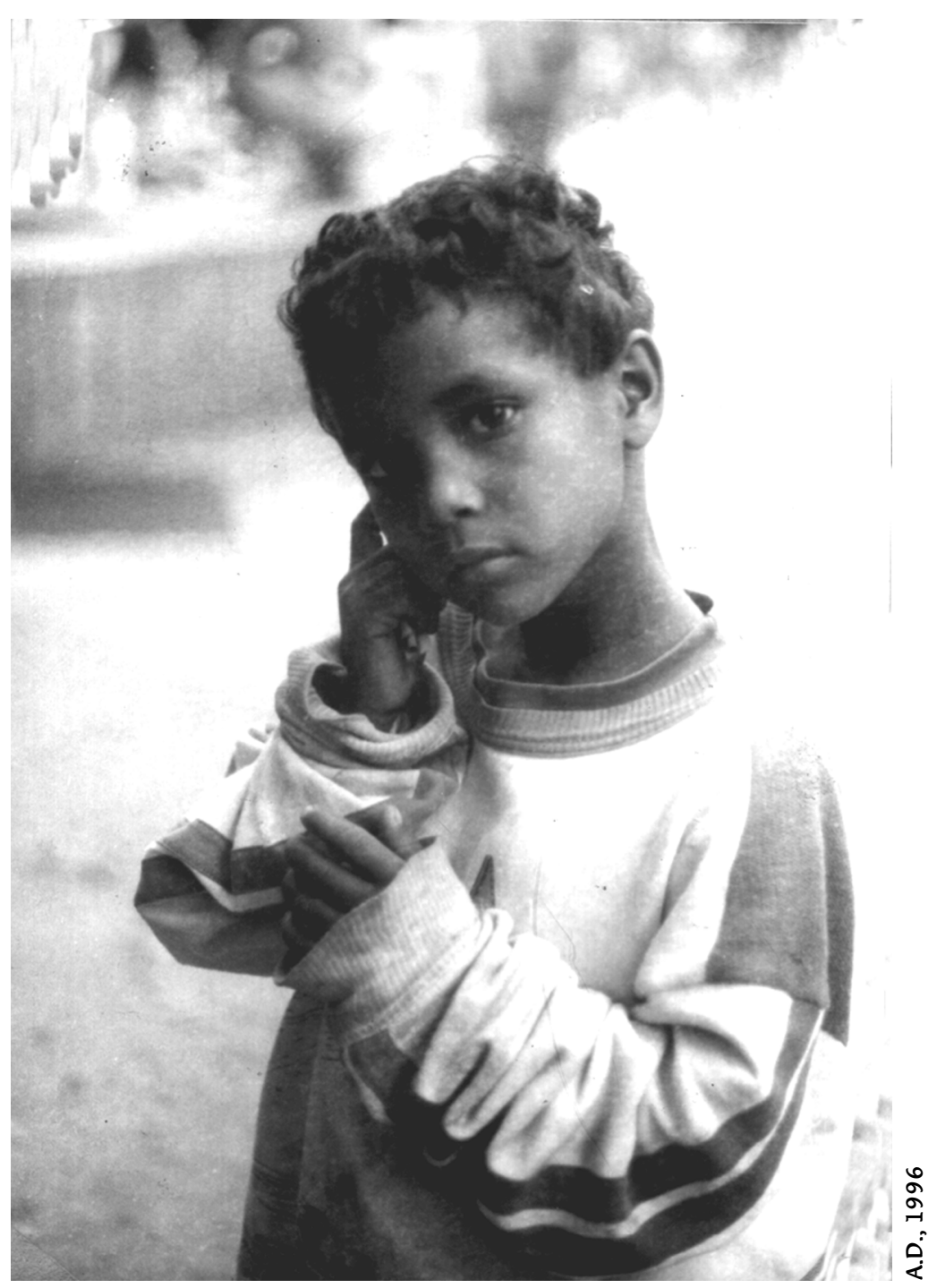

